\title{
Increased Isolation and Characterization of Shigella sonnei Obtained from Hospitalized Children in Tehran, Iran
}

\author{
Reza Ranjbar' ${ }^{1}$ Mohammad M. Soltan Dallal' ${ }^{2}$ Malihe Talebi ${ }^{3}$, and Mohammad R. Pourshafie ${ }^{3}$ \\ 'Molecular Biology Research Center, Baqiyatallah University of Medical Sciences, Tehran, Iran, '2Department of Pathobiology, \\ School of Public Health and Institute of Public Health Research, Tehran University of Medical Science, and ${ }^{3}$ Department of \\ Microbiology, Pasteur Institute of Iran, Tehran, Iran
}

\begin{abstract}
Shigella flexneri has been the most frequent cause of shigellosis in children in Iran. To evaluate the changes in frequency of serogroups, 302 Shigella species were isolated in 2003 from hospitalized children, aged less than 12 years, with acute diarrhoea in Tehran, Iran. The number of collected S. sonnei, S. flexneri, S. boydii, and $S$. dysenteriae isolates was 178 (58.9\%), 110 (37.4\%), 10 (3.3\%), and 4 (1.3\%) respectively. Most (94\%) S. sonnei isolates were resistant to co-trimoxazole. They were, however, relatively or completely sensitive to 15 commonly-used antibiotics. The extracted plasmids showed 12 different profiles with two closelyrelated patterns constituting 70\% of the total isolates. Ribotyping, using PvuII, HindIII or SalI restriction enzymes, generated a single pattern for all $S$. sonnei isolates. Data suggest that $S$. sonnei has become the predominant serogroup in children in the hospitals of Tehran.
\end{abstract}

Key words: Antibiotic resistance; Antibiotics; Drug resistance, Microbial; Dysentery, Bacillary; Ribotyping; Shigella sonnei; Iran

\section{INTRODUCTION}

Shigella is the major cause of diarrhoeal diseases in both developing and developed countries (1). In some developing countries, it was made up of $10 \%$ of all diarrhoeal cases during the 1990s among children aged $\leq 5$ years (2).

Of the Shigella species, Shigella flexneri and S. sonnei are the most prevalent serogroups found in developing and industrialized countries respectively. $S$. dysenteriae is seen mostly in South Asia and sub-Saharan Africa, and S. boydii has been reported worldwide with about $4 \%$ of the total shigellosis cases (1).

For many years, $S$. flexneri has been the predominant isolate in Iran $(3,4)$. The present study was conducted to examine the prevalence of Shigella spp., antibiotic susceptibility patterns, and genetic character-

Correspondence and reprint requests should be addressed to:

Dr. Mohammad R. Pourshafie

Department of Microbiology

Pasteur Institute of Iran

Tehran

Iran

Email: pour@pasteur.ac.ir ization of S. sonnei isolates. We report here for the first time that $S$. sonnei was the most frequent isolate among shigellosis cases in children in Tehran.

\section{MATERIALS AND METHODS}

\section{Patients}

The study included all patients, aged less than 12 years, with diarrhoea (three times or more watery or soft defaecations per 24 hours that had lasted for $\leq 7$ days, fever, abdominal pain, tenesmus with or without nausea, and vomiting), who were admitted to three large hospitals: Children Medical Center, Mofid Hospital, and Millad Hospital, in Tehran, Iran, during 2003.

A single specimen was obtained from each patient, and rectal swabs were collected from patients on the day of admission at the hospital. When the isolates were identified as Shigella by the conventional methods (5), these were serotyped using slide agglutination with specific antisera (MAST Group LTD, Merseyside, UK).

\section{Testing of antimicrobial susceptibility}

Antimicrobial susceptibility test was performed according to the standard guideline of the Clinical 
and Laboratory Standards Institute (6) using 16 antibiotic discs (Becton Dickinson and Company, Sparks, MD, USA), such as ampicillin (10 $\mu \mathrm{g})$, cefixime $(5 \mu \mathrm{g})$, cefotaxime $(30 \mu \mathrm{g})$, ceftazidime ( $30 \mu \mathrm{g})$, ceftizoxime $(30 \mu \mathrm{g})$, cephalothin $(30 \mu \mathrm{g})$, cephalexine $(30 \mu \mathrm{g})$, amikacin $(30 \mu \mathrm{g})$, gentamicin $(10 \mu \mathrm{g})$, kanamycin $(30 \mu \mathrm{g})$, ciprofloxacin $(5 \mu \mathrm{g})$, nalidixic acid $(30 \mu \mathrm{g})$, chloramphenicol $(30 \mu \mathrm{g})$, nitrofurantoin $(300 \mu \mathrm{g})$, furazolidone $(100 \mu \mathrm{g})$, and co-trimoxazole $(1.25 / 23.75 \mu \mathrm{g})$. Escherichia coli ATCC 25922 was used as a quality-control strain.

\section{Plasmid profiling}

A high-pure plasmid isolation kit (Roche, Mannheim, Germany) was used for isolating bacterial plasmids as per the instructions of the manufacturer. Extracted plasmids were then separated on a $0.8 \%$ agarose gel in Tris-borate-EDTA buffer (TBE $\times 1)(\mathrm{pH} 8.2)$ by electrophoresis. The strains were grouped depending on the pattern of the plasmid DNA bands. The banding patterns were interpreted by Dice analysis and clustered by the unweighted pair group method with arithmetic averages (UPGMA) with Gelcompar II, version 4.0 (Applied Maths, Sint-Matens-latem, Belgium).

\section{Ribotyping}

Ribotyping was performed using standard methods as reported in the previous studies (7). Bacterial DNA was digested with restriction enzymes (PvuII, Hin$d$ III, SalI) under the conditions recommended by the manufacturer (Roche Diagnostics, Mannheim, Germany). Digested DNA fragments were resolved on a $0.8 \%$ agarose gel in Tris-borate-EDTA buffer $(\mathrm{pH}$ 8.2) and then transferred onto nylon membrane by the alkali-blotting procedure with a vacuum blotter. Hybridization was performed with the probes labelled with digoxigenin-11-dUTP (DIG) (7). The membranes were then visualized by adding alkaline phosphate-conjugated anti-digoxigenin antibody (Roche Diagnostic GmbH, Mannheim, Germany) and 5-bromo-4-chloro-3-indolyl phosphate substrate and nitroblue tetrazolium. Citrobacter koseri strain CIP 105177 (collection: de l'Institut Pasteur) DNA was cleaved by $M l u \mathrm{I}$ restriction endonuclease, and the fragments were used as molecular size standards.

\section{RESULTS}

Of 3,050 patients with acute diarrhoea, 302 were diagnosed as having shigellosis based on clinical presentations and laboratory findings. The isolated Shigella strains were distributed thus: S. sonnei 178
(58.9\%), S. flexneri 110 (36.4\%), S. boydii 10 (3.3\%), and $S$. dysenteriae 4 (1.3\%).

Results of further examination of the $S$. sonnei strains showed that most $(\geq 94 \%) S$. sonnei isolates were resistant to co-trimoxazole, and $\leq 6 \%$ of the isolates were resistant to nalidixic acid, ampicillin, chloramphenicol, cefixime, and kanamycin. None of the tested isolates was resistant to ceftizoxime, ceftazidime, gentamicin, ciprofloxacin, amikacin, furazolidone, cephalothin, cefotaxime, cephalexine, and nitrofurantoin. Only $2.6 \%$ of the isolates were resistant to $\geq 3$ antibiotics (Table).

Plasmid analysis of clinical isolates of $S$. sonnei resulted in 12 different plasmid profiles with 2-9 DNA bands (Fig. 1). The plasmids larger than $20 \mathrm{~kb}$ were not analyzed because of their instability $(8,9)$. Furthermore, the plasmid isolation kit, used in this study, is suitable for purification of small plasmids. Figure 1 shows that some DNA bands (5.1 and 2.0 kbp) were evident in most strains. No similarity in the plasmid pattern between our clinical isolates and ATCC type strain 9290 was observed. The $S$. sonnei isolates containing the plasmid profile labelled as P2 and P13 harboured the lowest (3) and the highest (9) number of DNA bands respectively. P3 (39\%) was the dominant type of plasmid profile, followed by P6 (31\%) (Table).

Ribotyping was performed using three restriction enzymes, including PvuII, HindIII, and SalI, for all the $S$. sonnei isolates (Fig. 2). Ribotyping using SalI produced seven fragments ranging from 2.0 to $12.5 \mathrm{kbp}$. The highest number of DNA fragments was obtained when DNA was digested with PruII restriction enzyme, resulting in 13 fragments ranging from 1.8 to $14 \mathrm{~kb}$. HindIII showed 11 bands each from 2.4 to $10 \mathrm{kbp}$. Only a single ribotype pattern was observed using each of the restriction enzymes.

\section{DISCUSSION}

S. sonnei has been the predominant Shigella spp. in Europe and North America (10). Whereas, S. flexneri has been reported to be the most frequent Shigella spp. in many developing countries, including the Middle East region (11).

In the previous years, several investigators in Tehran reported that the majority (61\%) of shigellosis cases in all age-groups were caused by $S$. flexneri (61\%), followed by S. sonnei $(31 \%)(3,4)$. The results of this study have shown that $S$. sonnei has replaced $S$. flexneri as the predominant serogroup in children aged less than 12 years in the hospitals in Tehran. More re- 


\begin{tabular}{|c|c|c|c|}
\hline $\begin{array}{l}\text { Plasmid } \\
\text { pattern }\end{array}$ & $\%$ of isolates & $\begin{array}{l}\text { Resistance } \\
\text { pattern (\%) }\end{array}$ & $\begin{array}{l}\text { Resistance } \\
\text { phenotype }\end{array}$ \\
\hline P1 & ATCC $9290^{*}$ & - & - \\
\hline P2 & 1.3 & R4 (1.3) & SXT, K \\
\hline P3 & 38.7 & $\begin{array}{c}\text { R1 (32.5) } \\
\text { R2 (5) } \\
\text { R4 (1.3) }\end{array}$ & $\begin{array}{c}\text { SXT } \\
\text { SXT, NA } \\
\text { SXT, K }\end{array}$ \\
\hline P4 & 6.2 & $\begin{array}{c}\text { R1 (5) } \\
\text { R3 (1.3) }\end{array}$ & $\begin{array}{c}\text { SXT } \\
\text { K }\end{array}$ \\
\hline P5 & 1.3 & R1 (1.3) & SXT \\
\hline P6 & 31.2 & $\begin{array}{c}\text { R1 (28.8) } \\
\text { R7 (1.3) } \\
\text { R5 (1.3) }\end{array}$ & $\begin{array}{c}\text { SXT } \\
\text { AM, SXT, K } \\
\text { SXT, CFM }\end{array}$ \\
\hline P7 & 3.8 & R1 (3.8) & SXT \\
\hline P8 & 3.8 & R1 (3.8) & SXT \\
\hline P9 & 1.3 & R6 (1.3) & SXT, NA, C, K \\
\hline P10 & 2.5 & R1 (2.5) & SXT \\
\hline P11 & 6.2 & R1 (6.2) & SXT \\
\hline P12 & 1.3 & R1 (1.3) & SXT \\
\hline P13 & 2.5 & R1 (2.5) & SXT \\
\hline
\end{tabular}

Fig. A UPGMA dendrogram showing distribution of plasmid profiles of S. sonnei isolates UPGMA, Dice coefficient

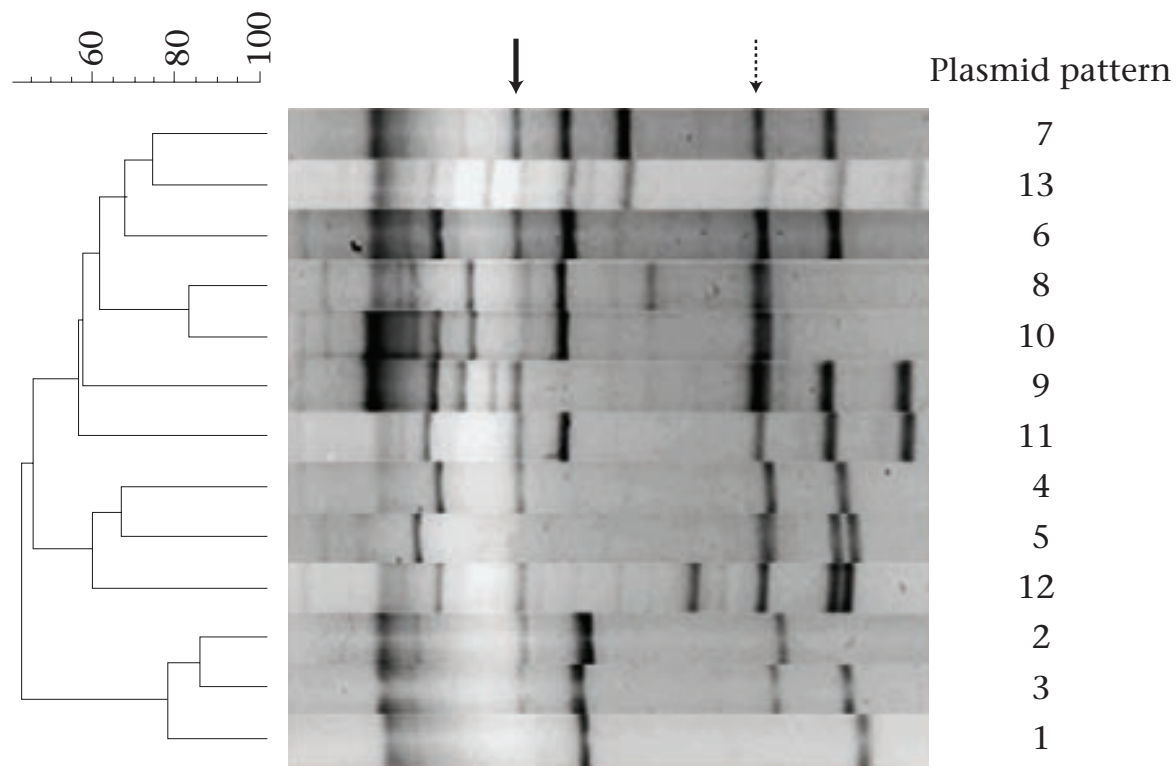

Lane 1=Plasmid profile of type strain ATCC 9290; Lane 2-13: Representative plasmid profiles of clinical samples. Solid arrow and broken arrow indicate 5.1 and 2.0 kbp DNA bands evident in most isolates; UPGMA=Unweighted pair group method with arithmetic averages

cently, Farshad and colleagues also identified S. sonnei as the most prevalent Shigella species in Shiraz, Iran, in a six-month study conducted in 2003 (12).
A multicentre study has shown that $S$. flexneri has been the most frequent isolate in Bangladesh, China, Pakistan, Indonesia, and Viet Nam (13). In the 
Fig. 2. Ribotyping of S. sonnei strain

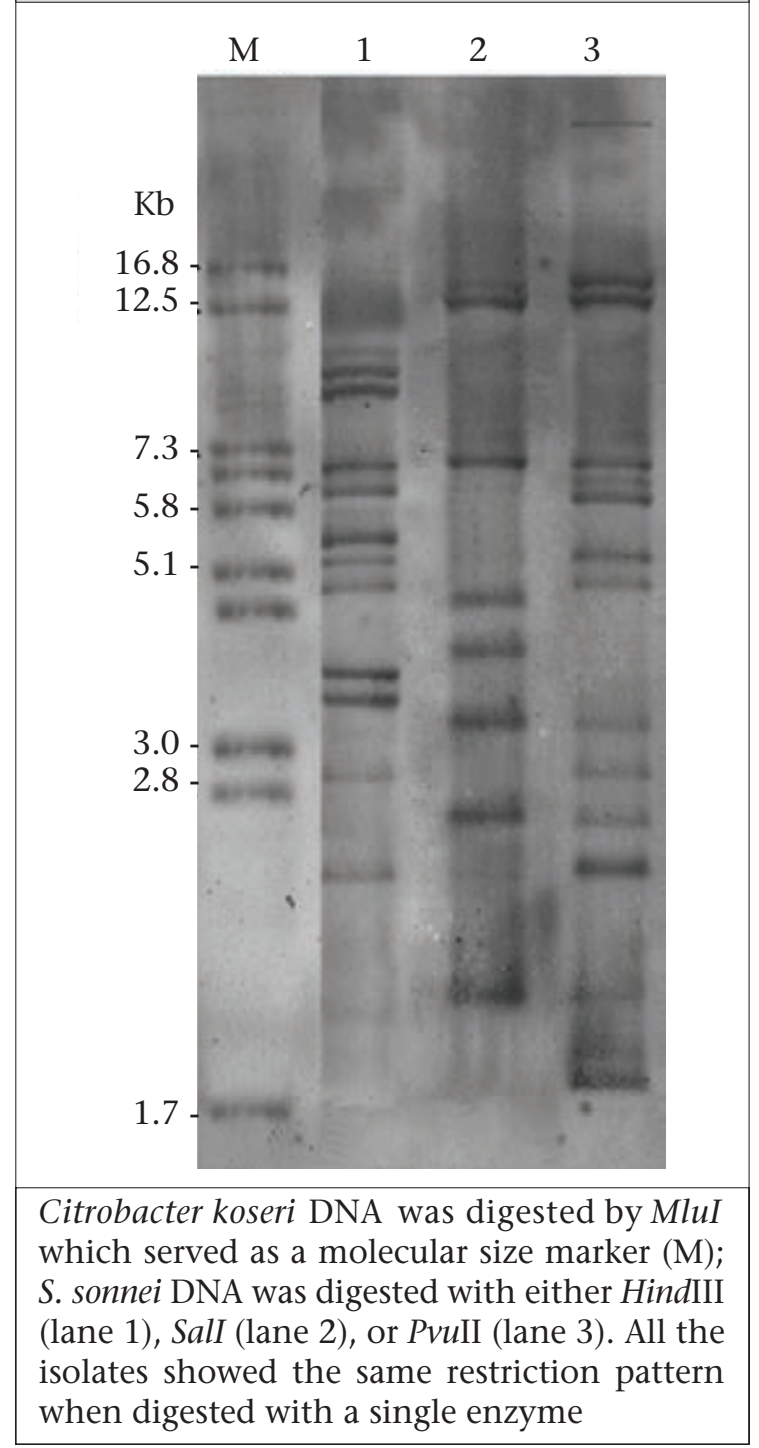

same report, $S$. sonnei has been shown as the most predominant isolate in Thailand. It was suggested that the reason for $S$. sonnei to be the principal isolate is the fact that Thailand is rapidly becoming an industrialized country (13). Similarly, Tehran is on the verge of becoming an industrialized city, and the decrease in the proportion of $S$. flexneri and an increase in $S$. sonnei may reflect the hygienic improvement in Tehran during recent years. Such a shift in the serotypes of Shigella has also been reported from India and Chile $(14,15)$.

The resistance of Shigella isolates to the first-line antimicrobial agents has been reported in a number of countries and is increasing worldwide with increased mortality (16). With the exception of co-trimoxazole, the large majority $(87 \%)$ of the isolates were relatively sensitive to 15 other antibiot- ics tested, indicating that the resistance of $S$. sonnei to drugs is not at an alarming rate in Iran. In the United States, the most common resistance among S. sonnei isolates was against ampicillin (77\%) and co-trimoxazole (37\%) (17). An increased resistance has been reported in developing countries, such as Chile and Bangladesh, for ampicillin (82\%), cotrimoxazole (65\%), and chloramphenicol (49\%) $(15,18)$.

Genetic characterization by plasmid profiling and ribotyping was also performed on our S. sonnei isolates. Tacket and colleagues investigated the plasmid profile of $10 \mathrm{~S}$. sonnei isolates and found 10 different patterns (19). In other studies, 61 S. sonnei strains resulted in identification of 42 distinct plasmid patterns (20). These studies may suggest the existence of a large number of different plasmids in the $S$. sonnei populations. We found 12 different plasmid patterns among our $S$. sonnei isolates. The presence of a common 5.1-kbp plasmid band was evident when comparing the plasmid bands in our samples with the report by other investigators $(8,21)$, suggesting a widespread dissemination of this plasmid DNA among $S$. sonnei isolates in different regions of the world.

Although some researchers have obtained variable results with ribotyping, the technique has been indicated to be useful for epidemiological studies of $S$. sonnei (22). Hinojosa-Ahmuda and colleagues have found six ribotypes when $100 \mathrm{~S}$. sonnei were studied using SalI restriction enzyme (23). Nastasi and colleagues have also found 13 ribotypes by examining $432 \mathrm{~S}$. sonnei isolates (24). Several investigators have reported the presence of a single ribotype pattern in their $S$. sonnei isolates which were obtained from outbreaks or sporadic cases (9). In our study, we also observed a single ribotype pattern among the $S$. sonnei isolates collected in Tehran.

The results suggest that $S$. sonnei has replaced $S$. flexneri as the predominant serogroup in children aged less than 12 years in the hospitals in Tehran. The single ribotype dominance was also supported by the data that $70 \%$ of the isolates harboured closely-related plasmid patterns labelled as P3 and P6. The dominance of an $S$. sonnei ribotype is interesting when it is considered that the isolates were obtained from different hospitals located in a large geographical area in Tehran. The results further confirm that continuous monitoring is needed for over a prolonged period in Tehran to detect the changes in the distribution of serotypes and the antimicrobial resistance pattern of Shigella. 


\section{ACKNOWLEDGEMENTS}

This research was supported in part by a grant from Tehran University of Medical Sciences and Pasteur Institute of Iran.

\section{REFERENCES}

1. Kotloff KL, Winickoff JP, Ivanoff B, Clemens JD, Swerdlow DL, Sansonetti PJ et al. Global burden of Shigella infections: implications for vaccine development and implementation of control strategies. Bull World Health Organ 1999;77:651-66.

2. Ferreccio C, Prado V, Ojeda A, Cayyazo M, Abrego P, Guers L et al. Epidemiologic patterns of acute diarrhea and endemic Shigella infections in a poor urban setting in Santiago, Chile. Am J Epidemiol 1991;134:614-27.

3. MoezArdalan K, Zali MR, Soltan-Dallal MM, Hemami M, Salmanzadeh-Ahrabi S. Prevalence and pattern of antimicrobial resistance of Shigella species among patients with acute diarrhoea in Karaj, Tehran, Iran. J Health Popul Nutr 2003;21:96-102.

4. Nikkah J, Mehr-Movahead A. Antibiotic resistance among Shigella species isolated in Tehran, Iran. Ann Trop Med Parasitol 1988;82:481-3.

5. Murray PR, Baron EJ, Pfaller MA, Tenover FC, Yolken FC editors. Manual of clinical microbiology. 6th ed. Washington, DC: American Society for Microbiology, 1995. 1,482 p.

6. Clinical and Laboratory Standards Institute. Performance standards for antimicrobial susceptibility testing; fifteenth informational supplement. Approved standard M100-S15. Wayne, PA.: Clinical and Laboratory Standards Institute, 2005.

7. Pourshafie M, Grimont F, Saifi M, Grimont PA. Molecular epidemiological study of Vibrio cholerae isolates from infected patients in Teheran, Iran. J Med Microbiol 2000;49:1085-90.

8. Litwin CM, Leonard RB, Carroll KC, Drummond WK, Pavia AT. Characterization of endemic strains of Shigella sonnei by use of plasmid DNA analysis and pulsed-field gel electrophoresis to detect patterns of transmission. J Infect Dis 1997;175:864-70.

9. Liu PYK, Lau YJ, Hu BS, Shyr JM, Shi ZY, Tsai WS et al. Analysis of clonal relationships among isolates of Shigella sonnei by different molecular typing methods. J Clin Microbiol 1995;33:1779-83.

10. Public Health Laboratory Service. A foodborne outbreak of Shigella sonnei infection in Europe. Commun Dis Rep CDR Wkly 1994;4:115.

11. Kagalwalla AF, Khan SN, Kagalwalla YA, Alola S, Yaish H. Childhood shigellosis in Saudi Arabia. Pediatr Infect Dis J 1992;11:215-9.

12. Farshad S, Sheikhi R, Japoni A, Basiri E, Alborzi A. Characterization of Shigella strains in Iran by plasmid profile analysis and PCR amplification of ipa genes. $J$ Clin Microbiol 2006;44:2879-83.

13. Von Seidlein L, Kim DR, Ali M, Lee H, Wang X, Thiem VD et al. A multicentre study of Shigella diarrhea in six Asian countries: disease burden, clinical manifestations and microbiology. Plos Med 2006;3:e353.

14. Dutta S, Rajendran K, Roy S, Chatterjee A, Dutta P, Nair GB et al. Shifting serotypes, plasmid profile analysis and antimicrobial resistance pattern of Shigella strains isolated from Kolkata, India during 19952000. Epidemiol Infect 2002;129:235-43.

15. Fulla N, Prado V, Duran C, Lagos R, Levine MM. Surveillance for antimicrobial resistance profiles among Shigella species isolated from a semirural community in the northern administrative area of Santiago, Chile. Am J Trop Med Hyg 2005;72:851-4.

16. Lee, JC, Oh JY, Kim KS, Jeong YW, Cho JW, Park JC et al. Antimicrobial resistance of Shigella sonnei in Korea during the last two decades. APMIS 2001;109:228-34.

17. Centers for Disease Control and Prevention. National antimicrobial resistance monitoring system for enteric bacteria (NARMS): 2002; human isolates final report. Atlanta, GA: Centers for Disease Control and Prevention, 2004. (http://www.cdc.gov/narms/naaua 1/2002/2002ANNUALREPORTFINAL.pdf, accessed on 5 July 2007).

18. Sur D, Niyogi SK, Sur S, Datta KK, Takeda Y, Nair GB et al. Multidrug resistant Shigella dystenteriae type 1: forerunners of a new epidemic strain in Eastern India. Emerg Infect Dis 2003;9:404-5.

19. Tacket CO, Shaid N, Huq MI, Alim ARM, Cohen ML. Usefulness of plasmid profiles for differentiation of Shigella isolates in Bangladesh. J Clin Microbiol 1984;20:300-1.

20. Tsong-Ming L, Chang LL, Chang CY, Wang JC, Pan TM, Wang TK et al. Molecular analysis of Shigella sonnei isolated from three well-documented outbreaks in school children. J Med Microbiol 2000;49:355-60.

21. Litwin, CM, Ryan KJ, Chipowsky S, Storm A, McCombie S. Molecular epidemiology of Shigella sonnei in Pima county, Arizona: evidence for a Mexico-related plasmid. J Infect Dis 1990;161:797-800.

22. Mendoza M.C, Martin MC, Gonzalez-Hevia MA. Usefulness of ribotyping in a molecular epidemiology study of shigellosis. Epidemiol Infect 1996; 116:127-35.

23. Hinojosa-Ahumada M, Swaminathan B, Hunter S, Cameron DN, Kiehlbauch JA, Wachsmuth IK et al. Restriction fragment length polymorphisms in rRNA operons for subtyping Shigella sonnei. J Clin Microbiol 1991;29:2380-4.

24. Nastasi A, Pignato S, Mammina C, Giammanco G. rRNA gene restriction patterns and biotypes of Shigella sonnei. Epidemiol Infect 1993;110:23-30. 